January 6, 2004

\title{
Encroached Entitlements: \\ Corruption and Appropriation of Irrigation Water in Southern Punjab (Pakistan)
}

\author{
by \\ Jean-Paul Azam \\ University of Toulouse (ARQADE and IDEI), \\ Institut Universitaire de France, and CSAE, Oxford. \\ and \\ Jean-Daniel Rinaudo \\ BRGM, Lingolsheim.
}

Acknowledgements : We wish to thank Pierre Strosser for his help in the field work, and G. V. Skogerboe, then Director of IIMI (Pakistan), for his support, without implicating in any way. Comments by Kaushik Basu, Bruno Biais, Jean-Jacques Laffont, Martin Ravallion and Dominique van de Walle, and by participants in seminars at Bocconi, Cornell and Toulouse, where this paper has been presented, as well as a useful discussion with Hanan Jacoby, are also gratefully acknowledged, with the same caveat. This paper has been written while JeanDaniel Rinaudo was with CEMAGREF in Montpellier.

Corresponding author : Jean-Paul Azam, ARQADE, University of Toulouse, 21 Allée de Brienne, 31000 Toulouse, France.

E-mail : azam@univ-tlse1.fr 
The relationships between the type of property rights prevailing in a country and its political system have been central to political economy, at least since Karl Marx's analysis of capitalism. His discussion remained of the all-or-nothing sort, with the type of private property characteristic of the bourgeois society being regarded as securely enforced by the legal system, while the collective ownership prevailing under a communist system would be immune from any type of private appropriation. In the recent literature, economists have tackled more nuanced issues, showing that property rights can be imperfectly defined or uncertain in some countries, and are not necessarily enforced 'from above' in a reliable way. For example, La Porta et al. (1998) analyze the difference in the legal protection of the investor's rights afforded by the Anglo-Saxon Common Law system and by the French and German Civil Law systems, which provide them with less secure property rights. They suggest that this impinges on the concentration of ownership of large public companies, an important characteristic of modern capitalism. The practical importance of the various shades of property rights for investment has been brought out in particular by Besley (1995), who has shown theoretically that various channels of influence create a negative link between uncertain or partial property rights and investment, with an application to rural Ghana. In his data set, he is able to distinguish between six different rights : "the rights to sell, rent, gift, mortgage, pledge, or bequeath each field", which are not necessarily all present under the 'ownership' umbrella.

Various responses to imperfect property rights can be observed in different societies, as they give rise to different types of substitutes, whereby investors try to secure their control over the returns to their investment. Private agents need to spend some resources in enforcing their property rights, in nearly all societies. However, de Meza and Gould (1992) have shown that the private enforcement of property rights is liable to create some inefficiency in a market economy. The mechanism emphasized in their paper is based on the particular externality that is created by the private enforcement of property rights : by restricting access to the enclosed sites, the private decision to enclose one's estate diverts labor to the remaining free-access sites, and thus increases congestion there. Multiple equilibria can arise in this model, with either all sites remaining in free access, or all sites being enclosed, when enforcement costs 
are in a given range. In other cases, only a fraction of the sites are enclosed, depicting a society where property rights are only enforced by a fraction of the population. Enforcement in the de Meza-Gould model is again of the all-or-nothing kind, while casual observation suggests that the probability of being robbed is never strictly zero in the real world, and that one can invest resources for reducing it. Grossman and Kim (1995) analyze a model where individuals can invest resources both in predation and in defense, showing that in equilibrium, property rights will be less than fully secure. In a related model, Hirshleifer (1995) brings out nicely how the prevailing political system and the security of property rights are related. Depending on the parameters of the technology of production and of the technology of appropriation, conflict, and struggle, this model can describe a stable anarchic equilibrium, or the emergence of dictatorship, or of other forms of political organization. The assumed technology of appropriation and conflict is related to the type of lottery introduced by Tullock (1967) in the rent-seeking literature, and Neary (1997) presents an interesting comparison of these two types of models. The model presented below has a lobbying component, where a related assumption is made.

The present paper shows that this range of issues is of wider application, where individuals may have to invest resources in the defense of other types of entitlements against the predatory behavior of other agents. This analysis is motivated by the case of a publicly provided private good, namely irrigation water ${ }^{1}$, with an empirical application to a particular irrigation scheme in the Chishtian area (Pakistan). Hence, in the terminology introduced by Sen (1981), the type of entitlement analyzed here is a mongrel of a "market-based entitlement", insofar as farmers have to pay a fee in exchange for the water that they get from the irrigation canal, and a "transfer entitlement", as the fee actually paid falls far below the marginal cost of delivering the water. There, corruption enables some rich farmers to encroach on the water quotas to which poorer farmers are entitled, while both types of farmers can also invest resources in political lobbying, engaging in a contest that affects the

\footnotetext{
${ }^{1}$ According to some estimates, nearly half of the irrigation water in the world is gathered privately (private wells, small irrigation systems, etc.). Our analysis does not apply directly to these cases.
} 
security of their entitlement, or the expected cost of illegal appropriation ${ }^{2}$. Hence, we observe there an intricate system of corruption and political interference in the working of the irrigation network, which illustrates the relationships between some characteristics of the political organization and the weaknesses of the entitlement system ${ }^{3}$. While the formal entitlement of the poor farmer to a given quantity of water from the irrigation canal is based on the legal and regulatory frameworks, some secret deals between the rich farmer and the management of the irrigation network can reduce the strength of his legitimate claims. Then, political lobbying, aiming at increasing the probability of the law being enforced, is the only route open to the poor farmer for defending his entitlement. Of course, this triggers a contest, where the rich farmer invests resources for covering his corrupt practices. This irrigation system provides a unique opportunity to perform some empirical analysis of corruption, which is usually very difficult to observe and measure. In the Chishtian irrigation sub-system, as in some other irrigation systems, the technology of appropriation leaves some physical marks that can be measured, as it requires the modification of the outlets that deliver the water, which in turn requires the bribing of some officials. We use this information in the empirical analysis presented below.

Section 1 below briefly describes the setting in the Chishtian sub-division, presenting in some detail the irrigation system, as well as the socio-political background that determines the relative bargaining power of the different actors, as well as their political influence. Our knowledge of this area is based on the field work performed by one of us, who spent a total of three years there, in several visits ${ }^{4}$. This section also provides a modicum of the technical information required to understand both the empirical analysis and the theoretical developments presented below. In particular, it justifies the asymmetric information

\footnotetext{
${ }^{2}$ In some other areas, the social differentiation between the upstream and the downstream farmers is not as striking as in the Chishtian area. However, even with an equal initial endowment, we expect the upstream farmers to become richer than downstream farmers, in the long run, for reasons that will become obvious by reading the present paper.

${ }^{3}$ Davies (2004) discusses also corruption and water in South Asia, in the context of the public delivery of water and sanitation services.

${ }^{4}$ We wish to acknowledge, without implicating in any way, the hospitality of the International Irrigation Management Institute (IIMI), Pakistan, for which Jean-Daniel Rinaudo worked for three years as an agricultural economist. The field research reported here would not have been possible without it. The IIMI has recently become the International Water Management Institute, as its range of activity has broadened.
} 
assumption made in the theoretical model, which prevents the corruption-free equilibrium from prevailing. A formal analysis of the game being played around this water allocation problem is provided in section 2. This model helps to articulate the various elements gathered by direct observation into a coherent game-theoretic framework, and allows to derive some comparative-static predictions, that are tested econometrically in section 3. Most probably, this model could be useful for shedding light on many other economic problems, where the public provision of a private good gives rise to encroachment, corruption, and political interference, because of its intrinsic theoretical interest. Moreover, the discipline imposed by the rigorous analysis of the problem yields one additional benefit : it points out the basic informational asymmetry that prevents the emergence of an efficient water market, which is the root cause of corruption and political interference. Consequently, our analysis of corruption is related to the one performed by Laffont and N'Guessan (1999), as they both assume that corruption is rooted in the possibility of hiding some action, and a comparison of these two models is provided in section 2. It differs substantially from the analyzes presented in Shleifer and Vishny (1993) and in Bliss and Di Tella (1997), which are based on market power, rather than on asymmetric information.

\section{The Irrigation System in the Chishtian Area : A Brief Narrative}

The Indus Basin Irrigation System in Pakistan, to which the Chishtian area under study belongs, is a very large network of canals, diverting the flows of the Indus river and its four tributaries. It is comprised of three major reservoirs, twelve link canals, more than 61,000 kilometers of primary and secondary canals, 1.6 million kilometers of tertiary and field channels, and it supplies irrigation water to more than 14 million hectares of agricultural land (Rinaudo, Strosser and Rieu, 1997). This enormous interconnected network of canals was built by the British between 1880 and 1930, and enlarged and improved on many occasions since. The system also includes 12,500 public tube wells and more than 400,000 private tube wells, located mainly in areas with relatively good quality groundwater. 
A typical canal command area of the Indus Basin Irrigation System is a ramified system consisting of : (i) a main canal diverting water from the Indus river or one of its four tributaries; (ii) a number of gated structures along the main canal that supply water to secondary canals, or distributaries ; (iii) a large number of non-gated structures, or outlets, spread along the distributary for supplying water to tertiary channels, or watercourses. Below the outlets, farmers share the canal water according to a weekly roster of water turns, or warabandi, with only one farmer at a time using the water flow supplied to the watercourse (Rinaudo, Strosser and Thoyer, 2000). In principle, the allocation of water is based on a concept of equity : the same quantity of water is officially allocated to each hectare of arable land ${ }^{5}$. Each hydraulic unit is entitled to an authorized discharge, proportional to its command area. At the level of the main canal, the staff of the irrigation agency operates the gated structures to regulate the flows in the main canal and to supply each distributary with its authorized discharge. Along the latter, the apportionment of the water between the watercourses is determined by the dimensions of the outlets. Below the outlet, the principle of equity is also supposed to govern the warabandi schedule, i.e. the duration of each individual's water turn, which is meant to be proportional to the size of his/her land holding.

However, several researchers have pointed out that the allocation of water is no longer governed by this concept of equity. Water turns are not allocated equitably among the users of a given watercourse (Bandaragoda and Rehman, 1995). Average discharges received by distributaries and watercourses are at variance with their official figures. Flows are no longer shared equitably among the different hydraulic units, with the tail areas bearing the bulk of water shortages (Bhutta and Vander Velde, 1992, Kuper, 1997). Various technical factors play a part in distorting the pattern of water distribution, like inadequate and variable inflow at the head of the main canal, important deposits of sediments that modify the topography of the canal, and the imperfect information available to the management of the irrigation system. However, the inequitable distribution is mainly due to the interference of water users with the management of the system, as farmers try to influence the decisions of the Provincial

\footnotetext{
${ }^{5}$ Barhan (1984, Chapter 16) disputes the equitable nature of this water distribution principle, which prevails also in India.
} 
Irrigation and Power Department (PIPD) staff. Such interference are increasingly reported in the media in Pakistan, and also by officials from the irrigation bureaucracy (Ullah, 1994), by donors (World Bank, 1994), and by policy makers (Government of Pakistan, 1993).

Rinaudo, Strosser and Thoyer (2000) report on their intensive fieldwork conducted in one irrigation sub-system located in south-east Punjab, in the Chishtian area, taking water from the Sutlej river, from the Suleimanki dam, and supplying water to approximately 75,000 hectares. This sub-division comprises 14 distributaries, supplying 503 outlets, with an additional 19 outlets along the main canal, supplying water to about 23,000 farms. Some canals are closed in winter when the water level is low in the rivers. With less than 200 millimeters of rainfall per year, cultivation there is not possible without irrigation water. The main crops grown are cotton in summer (Kharif season) and wheat in winter (Rabi season). Some rice, and a little sugarcane, are also grown in this area. A lot of qualitative information has been collected by informal interviews over a period of three years, and has been crosschecked, where relevant, by the physical measurement of infrastructures or discharges in the canals, wherever this was possible. Some quantitative data was also collected in one sample secondary canal : the geometry of the canal, the dimensions of the outlets, and the discharges at the head of the canal were actually measured. This provides some useful information for estimating approximately the extent of deviation of the actual water allocation from the official figures, as well as for providing an estimate of the value of the water diverted to the farmers. That study suggests that the potential collective action problems are kept under control within each watercourse command area. This concerns relatively small communities of farmers, of about 20 to 50 farmers, where social links are pretty strong, and very little cheating takes place at this level. Farmers can exchange their water turns across time, to cater for crops with different seasonal demands (Strosser, 1997, Ray and Williams, 2002) ${ }^{6}$.

\footnotetext{
${ }^{6}$ Compare with the discussion in Bardhan (1984, Chapter 16), which emphasizes the 'anarchy syndrome' in the scramble for water at the watercourse level in India, and the resulting inefficient and inequitable distribution of water among farmers below the outlet. Probably, the scarcity of water is more stringent in the examples that he discusses than in the Chishtian area, and this might make collective action problems among the farmers worse. Similarly, Ray and Williams (1999) discuss 'water theft' at the watercourse level in Maharashtra, and their importance for price policy. Similarly, Ray and Williams (2002) discuss cooperation among farmers at the watercourse level, i.e. below the outlets. Neither them, nor Bardhan, address the issue of competition between the groups of farmers, i.e. across watercourses, that is the focus of the present analysis.
} 
Similarly, Murgai et al. (1999) analyze the exchange of water as part of mutual insurance schemes at the watercourse level, in the same area. By far the most widely used method for increasing the quantity of water consumed by farmers is to obtain from the PIPD staff an enlarged outlet. This provides an increased flow of water for the whole agricultural season. Much less frequently, it happens also that the farmers from a watercourse area obtain a second outlet. The extra water allocation benefits all the farmers of the watercourse, while it is done at the expenses of other water users located several kilometers downstream along the distributary, and who do not belong to the same village or community. Very rarely, some farmers obtain an increase in the discharge at the head of the distributary, which benefits all the outlets located along this canal. Sometimes, farmers use also various methods for stealing directly the water from the canal, using flexible siphoning pipes, or by making cuts in the banks of the distributary, or by maneuvering the gates at night, for a few hours. When caught, these farmers are of course fined, but some bargaining occurs necessarily.

Using a hydraulic simulation model, Rinaudo, Strosser and Thoyer (2000) have been able to provide an estimate of the impact of the tampering of the outlets in 1994. They use the actual geometry of one of the secondary canals of the Chishtian sub-system with a command area of 16,000 hectares, and supplying 80 watercourses, as well as the discharge at the head of the canal, and the actual dimensions of the outlets as data in the model, and simulate the effect of restoring all the outlets to their official sizes. They show that a small number of farmers are thus able to appropriate illegally a sizable quantity of water, by tampering with 9 outlets, worth on average 55 US \$ per hectare and per year, with a maximum of 243 US \$ per hectare and per year, while the losses are spread over a larger number of farmers located downstream, supplied by 40 outlets, loosing on average 7 US \$ per hectare and per year, with a maximum of 23 US \$. By interviewing informally a large number of farmers and low-ranking irrigation officials, they estimate that the level of the bribes paid to the irrigation department officials vary between US \$ 140 and US \$ 430 per outlet and per year. Similar figures were obtained from interviews performed in other areas of South Punjab. Compared to the acreage concerned, the average bribe amounts to a small levy : about US \$ 1.4 per hectare, i.e. about $2.5 \%$ of the average rent appropriated illegally. However, there is a large variance in the data. 
The polity in the Chishtian area is dominated by nine families of quasi-feudal landlords, owning several hundreds, or even thousands, of hectares of land (Rinaudo, 2000). Their plots are located in approximately 200 watercourse areas, i.e. in $38 \%$ of the watercourses of the sub-division. Most of them belong to the Seyed caste, who claim to descend directly from the Prophet Muhammad. Three of them, concerned together by $20.3 \%$ of the watercourses, derive their power from a Sufi ancestor, a highly respected religious authority. This religious legitimacy provides them with a strong influence on the local population. Another family of this group of nine, owning land in $1.5 \%$ of the watercourses, is of direct descent from the former Kings of the Bahawalpur state, while two other families, concerned by $10.6 \%$ of the watercourses, belong to the local Rajput tribes Lakwera and Badera, who behave traditionally with a marked independence from the central government, and descend from the Joyias tribe, of the former Kings of the Sahahr Farid state. Another powerful family, concerned only by $0.4 \%$ of the watercourses, migrated from Afghanistan, and descends from the former Kings of Multan. The last powerful family from this group, owns land in $4.5 \%$ of the watercourses areas, and derives its power from its political background. All these families have some of their members engaged in some political activity, with elected mandates, as members of the federal or regional parliaments. These landlords rent out their land to tenants or sharecroppers, to whom they provide traditionally social, economic, and sometimes judiciary, protection and support. There are two other types of farmers in this area. Some capitalist farmers cultivate about 10 hectares of irrigated land, with some important investments in mechanical equipment (tractors, pump sets, ...) and in tube wells, occasionally hiring wage workers, renting some land on a fixed rent basis, and producing some high value cash crops. Jacoby et al. (2003) analyze tube-well irrigation and the market for groundwater in an area not far from the one that we study here, emphasizing the market power of the well owners. Lastly, there is a large number of small landholders, cultivating cotton and wheat on one or two hectares, and relying on the market for purchasing water and the services of mechanical equipment (Rinaudo, 2000).

The other main partition of the population that matters from a political point of view is between the local population proper, which used to live in this area before the British rule, 
and the settler population, which migrated from central Punjab or India, mainly between 1930 and 1960. The local population is mainly comprised of the powerful landlords, described above, and of their sharecroppers, who are heavily dependent on them. They account for $61 \%$ of the land owners, and cultivate $60 \%$ of the land. They speak Siraki and Riasti. Because of their secular presence in this area, these people claim a privileged access to its natural resources, land and water. The settlers arrived in the Chishtian area in two waves. In the 1930s, a large number of farmers came from central Punjab, and belong to the Arain and Jats castes of agriculturists, regarded as inferior to the Rajputs, descending from a caste of warriors. They speak Punjabi. Most of them are small to medium landowners, though a few of them have made significant investments in tractors and tube wells, and are part of the capitalist farmers described above. The second wave of migrants, called the Mohajirs, came after 1947, in the wake of the Indian independence and the separation of Pakistan. They often worked in clerical jobs before migrating, and have a higher educational level than the others. Although they speak various languages of the sub-continent, they are known for their strong solidarity links. As they arrived last in the area, they often own their land in the tails of the irrigation canals, where water supplies are irregular, and shortages are liable to occur. Most of them are small landowners or tenants, cultivating a few hectares of land.

Equipped with this background information, we are now in a position to analyze the model, which aims at capturing the main points of the political-economic game being played in the Chishtian sub-division. Most probably, the main features of this model could be applied in many other parts of the world, where an irrigation system gives rise to the diversion of water by some farmers, corruption, and political interference.

\section{The Model}

We restrict the analysis to the case of a secondary canal, or distributary, where two farmers are each officially entitled to getting a quantity of water $q$, measured in units of output $^{7}$. Each farmer represents in fact the group of farmers served by a watercourse, and we

\footnotetext{
${ }^{7}$ We assume an equal entitlement for each farmer, for notational simplicity, and nothing would be changed by assuming unequal water quotas, provided they were exogenous.
} 
assume that any potential collective action problem at this level is solved, in order to focus on the problems raised by the competition for water that takes place between these groups. The narrative presented above has shown that this is the crucial issue in the Chishtian area. However, the delivery of irrigation water in this canal is uncertain, so that the total quantity of water available is in fact $2 q-\varepsilon$, where $\varepsilon$ is an exogenous random variable, such that $E(\varepsilon)=0$, and $-q<\varepsilon<q$. This may capture both the effect of leakage, fluctuation of the flows in the river, or other natural causes of uncertain delivery, and the effect of the imprecise delivery of water to the secondary canal, by the irrigation authority, somewhere at a higher level. Because the water is delivered by gravitation, the opportunities offered to the two farmers depend on their location along the canal. The rich farmer's fields are located upstream, and he can exceed his water quota by diverting an extra quantity of water $\delta$, while paying a bribe, or baksheesh, $\beta$ to the irrigation official. Hence, his total consumption of water is $q+\delta$. The poor farmer's fields are located downstream, and he gets a quantity of water $q-(\delta+\varepsilon) \geq 0$, still expressed in units of output.

The crucial set of assumptions is concerned with the information available to each player when the various decisions are made. What we want to capture in a simple formulation is a process whereby the rich farmer bribes the irrigation official in January each year for getting an enlarged outlet which will determine the quantity of water supplied to the watercourse until next December. This is captured by $\delta$, which the downstream farmer is unable to observe at any point during the year for various reasons, including that his village is located several kilometers downstream, and he is not welcome to browse around. Hence, the poor farmer cannot observe accurately $\delta$, so that he is not in a position to negotiate a contract offering a bribe $\alpha$, either to the irrigation official or to the rich farmer, with a view to limit the quantity of water diverted upstream to any level $\delta$. In the Chishtian sub-division, the quantity diverted is related to the enlargement of the outlets, relative to their official size, which can only be observed during a short period of time, before the system is under water. It would be terribly time consuming, and practically impossible, for the poor farmers located downstream to collect regularly the type of information that we use below in our empirical analysis, in order to be in a position to offer contracts to the farmers located upstream. 
The total quantity of water that will be fed into the distributary during the year is a random variable, and nobody is able to observe the deviation from the planned quantity corresponding to the farmers' entitlements. This would require the daily observation of the water flow during more than 10 months. Moreover, the gauges that were once installed at the canal head, with a view to provide some information on the quantity of water entering the distributary, have been mostly destroyed, and left un-repaired. However, the uncertain delivery of water at the canal head is not the only source of uncertain supplies, as the quantity of water that an outlet can take from the canal is also affected by various natural (or not) causes, like some changes in the topography of the distributary, due to insufficient maintenance, for example. Our assumption of noisy observation captures these facts in an operational way.

At the end of the year, the poor farmer will have observed the shortfall in the water obtained relative to his entitlement $(\delta+\varepsilon)$, at least approximately, but this information cannot be used for conditioning a contractual transfer from the downstream farmer to the upstream one, for two reasons. First, the upstream farmer is in fact unable to observe this quantity of water, as this would require a year-long monitoring of the flow, just above the poor farmer's outlet, several kilometers downstream. In other words, $\varepsilon$ is not observed by anyone. Second, even if the upstream farmer happened to be able to perform this monitoring accurately, an unrealistic assumption, as seen above, no third party could be called upon to enforce a contract based on this information, which would not be verifiable, and would entail an illegal transfer from the poor farmer to the rich one, in return for the on-sale of stolen water. This would be especially true when the two farmers belong to groups of different ethnic origin. As seen above, in the Chishtian area, the poor farmers located at the tail of the distributaries are often post-1947 refugees, while the farmers located at the most favorable places upstream belong frequently to the original population.

Now, the game between these two farmers takes place in three stages, and involves other players. For the sake of simplicity, all the players are assumed risk neutral. The first stage of the game takes place in the political arena, where the two farmers engage in a lobbying contest. We use two black boxes to encapsulate the institutional environment in 
which the game takes place. The regulatory framework is such that the irrigation authority can send an inspector to examine the canal, who masters the technology for detecting any water diversion, i.e. to compare the size of the outlets to their official value. This can be done during the lean season, for a short period when the canals are emptied. If an inspector comes, he observes $\delta$ and imposes a sanction $z(\delta)\left(z^{\prime}(-)>0, z^{\prime \prime}(-)>0\right.$, and $\left.z(0)=0\right)$, determined by law, on the irrigation official. We assume that there are no corrupt inspectors, or that the political pressure described below ensures that they behave in the proper way. In the Indus Basin Irrigation System, of which the Chishtian sub-division belongs, the sanctions can range from a minor blame to the firing of the corrupt official. The group of farmers below the outlet cannot be fined collectively, so that the threat of sanction only affects the official. The second black box that we use for capturing the institutional background of the game is the probability $p(x, y)$ of the inspector coming to examine the canal, which depends on the efforts invested by the two farmers in lobbying politicians ${ }^{8}$. The poor farmer's lobbying effort, measured in units of output, is $x$, with a positive impact on $p(-)\left(p_{x}(-)>0\right)$, while the rich farmer's lobbying effort, measured in the same units, is $y$, with a negative impact on $p(-)\left(p_{y}(-\right.$ ) $<0$ ). This captures the high level of political interference in the management of the irrigation system that can be observed in the Chishtian area, as well as in the rest of the Indus Basin Irrigation System. We also assume decreasing returns to lobbying, i.e. that $p_{x x}(-)<0$ and $p_{y y}(-)>0$. The combination of these two black boxes allows to account both for the formal institutional framework, via $z(\delta)$, and for the informal institutional framework, via $p(x, y)$, as advocated by North (1990).

The third stage of the game takes place at the canal level, where the rich farmer and the irrigation official bargain over a $\{\delta, \beta\}$ contract, being both assumed to observe $\delta$ without noise. In the Chishtian area, this bargaining takes place every year during the lean season, exactly when the workers from the irrigation authority come with the officials to 'repair' the outlets before restoring the water flow. This is a secret deal, insofar as the poor farmer does

\footnotetext{
${ }^{8}$ The probability function $p(x, y)$ is akin to the success fraction in Hirshleifer (1995), and is standard in the rentseeking literature (e.g. Tullock, 1967). Lobbying by the poor farmers mainly takes the form of marching and demonstrating in Chishtian, which can be quite effective because of the disruption caused, while the rich ones use more discrete methods.
} 
not observe the outcome, once the outlet is under water. In the Chishtian area, it would be too costly for the poor farmers to monitor that no water is diverted upstream, because of the distance between the outlets, and because of the duration of the closure period: the outlets could be repaired apparently for a while, with an agreement to remove a few bricks just before the canal is opened again, at a date which is kept uncertain by a few days. The irrigation official and the rich farmers have also several means to keep the poor farmer at bay while settling their transaction, including, for example, keeping the date of the 'repairs' of the outlets secret, or sending simultaneously other teams of workers to 'repair' the outlets downstream. For the sake of completeness, we assume that the poor farmer can also offer bribes $\alpha^{M}$ and $\alpha^{R}$ to the irrigation official and the rich farmer, respectively, at the second stage of the game. Because no farmer has any power to tax the official, we obviously assume that all the bribes are subject to non-negativity constraints.

In order to analyze the sub-game perfect equilibrium of this three-stage game, we proceed backward in the usual way: we first solve step 3, given $p(-)$, and then we solve steps 2 and 1 , given the best-response function $\delta^{*}(p(-))$, which describes the quantity of diverted water anticipated by the two farmers. Now, for solving the last stage of the game, we use the generalized Nash bargaining solution (Rubinstein, 1982). We first define the break point. If no agreement between the rich farmer and the irrigation official is reached, the latter gets $\alpha^{M}$, the bribe paid by the poor farmer, if any, and the former gets $q+\alpha^{R}-y$, i.e. the water quota, plus the baksheesh paid by the poor farmer, if any, minus the amount invested in lobbying in the political arena. If an agreement is reached, the rich farmer will get additionally the value of the water appropriated $\delta$ minus the amount of the bribe given to the irrigation official $\beta$; the irrigation official gets additionally the value of the bribe, minus the expected value of the sanction $p(x, y) z(\delta)$. Therefore, denoting $0 \leq \eta \leq 1$ the rich farmer's bargaining power, the secret deal between the latter and the irrigation official will solve :

$$
\max _{\delta, \beta}(\delta-\beta)^{\eta}(\beta-p(x, y) z(\delta))^{1-\eta}
$$

The first-order conditions can be arranged to yield two equations :

(i) the efficient risk-taking condition : 
$p(x, y) z^{\prime}(\delta)=1$,

(ii) the rent-sharing rule :

$\beta=p(x, y) z(\delta)+\frac{1-\eta}{\eta}(\delta-\beta)$

Using equations (2) and (3), we can prove the following proposition :

Proposition 1 : In an interior solution, we have :

$$
\delta \geq \beta>p(x, y) z(\delta)
$$

Therefore, it is always profitable for the rich farmer and the irrigation official to engage in corruption in the last stage of the game, provided an interior solution exists. The latter is granted provided $z^{\prime}(0)<1$.

Proof : As $z(\delta)$ is strictly convex, we have $\delta z^{\prime}(\delta)>z(\delta)$, and, using the efficient risk-taking condition, this yields :

$$
\delta>\frac{z(\delta)}{z^{\prime}(\delta)}=p(-) z(\delta)
$$

Now, from the rent-sharing rule, we get :

$$
\beta=\delta-\eta(\delta-p(-) z(\delta)) \leq \delta
$$

Lastly, as $0 \leq p(-) \leq 1$, the existence condition for an interior solution follows from the efficient risk-taking condition. QED

Notice that we can derive from the rent-sharing rule an expression that determines the level of the bribe as a linear function of the amount of water diversion accepted by the irrigation official and of the expected cost of this decision :

$$
\beta=(1-\eta) \delta+\eta p(-) z(\delta)
$$


This expression can in turn be interpreted as an incentive contract that decentralizes the equilibrium bargain, giving the amount of the transfer from the rich farmer to the irrigation official as a function of the 'performance' of the latter. To check this point, maximize with respect to $\delta$ the official's objective function $\left(\alpha^{M}+\beta-p(-) z(\delta)\right)$, subject to the constraint (5); this yields the efficient risk-taking condition $(2)^{9}$. This interpretation relates nicely the bargaining power of the rich farmer to the power of the incentives provided to the irrigation official (see Laffont and Tirole, 1993): the power of the incentive provided to the irrigation official is lower, the higher the bargaining power of the rich farmer. In the limit, if the bargaining power of the rich farmer tends to one, then the baksheesh will just compensate the official for the expected cost of the sanction incurred if caught cheating. At the other extreme, if the bargaining power of the rich farmer falls to zero (an unlikely occurrence), then the latter will pay the full value of the additional water, as his rent falls to zero.

Now that we have established that the secret deal will take place in step 3 of the game, we need to characterize the main piece of information used in step 2 and 1, namely the bestresponse function governing the amount of water diverted.

Proposition 2: The best-response quantity of water diverted is decreasing with the probability of inspection :

$$
\delta=\delta^{*}(p(-)), \delta^{* \prime}(-)<0 .
$$

Proof : From the efficient risk-taking condition, we get by total differentiation :

$$
\frac{d \delta}{d p}=\frac{-z^{\prime}(\delta)}{p(-) z^{\prime \prime}(\delta)}<0 . \text { QED }
$$

Then, given the function $\delta^{*}(p(x, y))$, we analyze the first two stages of the game, assuming that the two farmers engage simultaneously in their lobbying efforts. Each farmer seeks to maximize his objective function, subject to the constraints (5), (6), and the nonnegativity constraints bearing on the different bribes, where appropriate. This leads immediately to the following result :

\footnotetext{
${ }^{9}$ Provided $\eta<1$.
} 
Proposition 3 : The poor farmer will bribe neither the irrigation official, nor the rich farmer, i.e. $\alpha^{M}=\alpha^{R}=0$.

Proof : The poor farmer's best response functions are derived from the following program :

$$
\begin{array}{ll}
\max & q-E(\delta+\varepsilon)-x-\alpha^{M}-\alpha^{R}, \\
\text { s.t. } & \delta=\delta^{*}(p(x, y)), \\
& \alpha^{M} \geq 0 \\
& \alpha^{R} \geq 0 \\
& x \geq 0 .
\end{array}
$$

As the two bribes appear with a negative sign in the objective function, and not in the constraint, they must be set to zero. QED

Proposition 3, which is in fact pretty obvious, formalizes the main reason why, in this model, an efficient water market that would enable the farmers to avoid engaging in political lobbying fails to emerge. As the poor farmer is not in a position to observe the quantity of water diverted by the rich farmer, he can offer no contracts conditional upon this information.

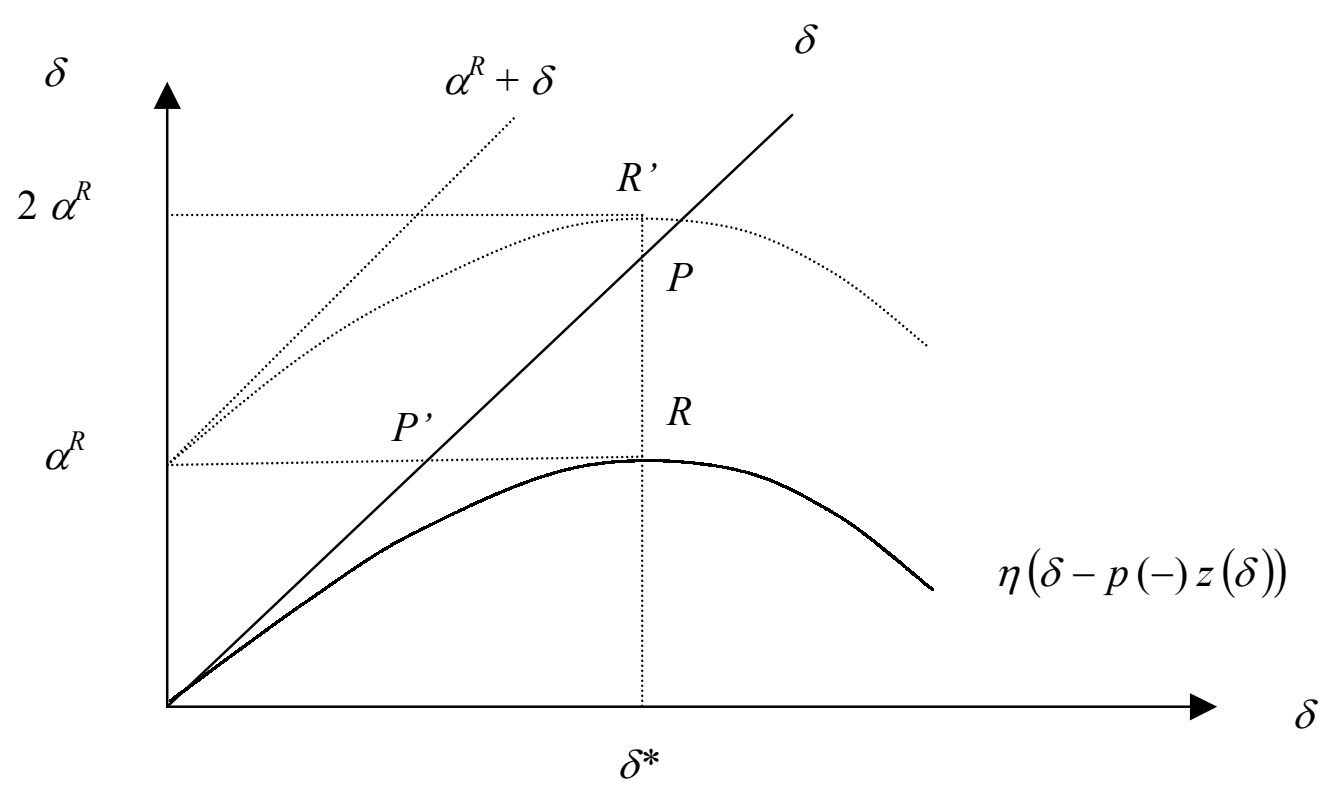

Figure 1: Stage-Two Gains of the Rich and Poor Farmers

Figure 1 helps to understand more intuitively the nature of the stage-two game. The horizontal axis measures the quantity of water diverted, in terms of income, while the vertical 
one measures the gains by the rich farmer, the irrigation official, and the state, as well as the loss incurred by the poor farmer. The ray through the origin labeled $\delta$ is the $45^{\circ}$ line.

The equilibrium described above is found at points $R$ and $P$. The bell-shaped curve represents the gain made by the rich farmer in the bargain with the irrigation official, and its maximum is at $R$, corresponding to a water-theft level of $\delta^{*}$. The expected loss to the poor farmer is the height of point $P$, corresponding to the income value $\delta^{*}$ of the water diverted. The $R P$ distance measures the value of the bribe, which includes the expected gain to the official and that of the state, via the fine. This diagram allows to bring out clearly the cost to the poor farmer of the moral hazard problem described above, which prevents him from adopting the role of the principal. In the absence of the asymmetric information problem discussed above, the poor farmer could choose to become the residual claimant, bearing all the uncertainty of the random flow, and offer the rich farmer a transfer $\alpha^{R}$, which would fulfil the latter's participation constraint. This is due to the assumed risk neutrality of the players, but could be generalized very easily to the case of risk aversion. This transfer would reduce the poor farmer's loss to $P^{\prime}$, and the official's gain to zero. However, because of the observation problem described above, such a contract would not prevent the rich farmer from striking a deal with the official, and blame the potential resulting shortage on a random shock to the total flow, whereas a negative $\varepsilon$ draw could even hide the theft entirely; this bargain would shift the bell-shaped curve upwards, allowing the new rich farmer's gain to reach point $R$ '. In this case, the poor farmer would in fact loose $\alpha^{R}+\delta *$. Anticipating correctly this problem, the poor farmer will not offer such a contract, i.e. an informal water market will not emerge across watercourses.

Rich Farmer's Choice

\begin{tabular}{l|l|c|c|}
\cline { 2 - 4 } & & Comply & Cheat \\
\cline { 2 - 4 } $\begin{array}{l}\text { Poor } \\
\text { Farmer's } \\
\text { Choice }\end{array}$ & Offer the $\alpha^{R}$ Contract & $\alpha^{R},-\alpha^{R}$ & $2 \alpha^{R},-\left(\alpha^{R}+\delta^{*}\right)$ \\
\cline { 2 - 4 } & Stay Put & Void & $\alpha^{R},-\delta^{*}$ \\
\cline { 2 - 4 } & &
\end{tabular}

Table 1: The Normal Form of Stage-2 Game 
Table 1 presents the normal form of this game, showing that it has the structure of a one-sided prisoner's dilemma. The poor farmer is choosing the row, and the rich one the column. In each cell, the first variable is the rich farmer's gain, while the second one is the poor farmer's one. While the north-west cell is the Pareto equilibrium, it cannot be sustained as a Nash equilibrium, as it is dominated by the north-east cell from the rich farmer's point of view. Therefore, the south-east cell is the Nash equilibrium of this game.

Notice that, because risk aversion or decreasing returns are assumed away, these different equilibria are socially equivalent from a utilitarian point of view. However, the $\alpha^{R}$ equilibrium would be preferred to the $\delta^{*}$ one for any distribution-sensitive social welfare function, as the poor farmer's income is probably well below that of the rich farmer and the irrigation official.

Therefore, the root cause of all the complicated system of corruption-cum-lobbying that we are analyzing here is the asymmetric information between the poor farmer, on the one hand, and the irrigation official and the rich farmer, on the other hand, which creates a moral hazard problem. Moreover, because of the bribery involved, it is clear that the irrigation authority has an incentive to make sure that the quantity of water diverted remains unobserved by the relevant people. In the case of the Chishtian sub-division, we have observed that the irrigation officials have left the gauges deteriorate without repairing them, although the information that they provided was of limited value to the farmers.

Now, we can characterize the sub-game perfect equilibrium of this game as follows, by turning to stage one. After substituting the constraints in the relevant objective functions, the sub-game perfect equilibrium is a pair of lobbying efforts $\left\{x^{*}, y^{*}\right\}$, together with the derived values of $\left\{\delta^{*}, \beta^{*}\right\}$, that solves simultaneously:

$$
\max _{\mathrm{x}} q-\delta^{*}(p(x, y))-x
$$

and

$$
\max _{\mathrm{y}} q+\eta\left[\delta^{*}(p(x, y))-p(x, y) z\left(\delta^{*}(p(x, y))\right)\right]-y \text {. }
$$

From the first-order conditions, and using the envelope theorem, the equilibrium pair of lobbying efforts must solve the following pair of partial-derivative equations : 


$$
\frac{\partial p}{\partial x}=\frac{-1}{\delta^{* \prime}(p(-))}
$$

and

$$
\frac{\partial p}{\partial y}=\frac{-1}{\eta z\left(\delta^{*}(p(-))\right)}
$$

These two conditions make it clear that the equilibrium outcome depends heavily on the socio-political framework (via the $p(-)$ function, and its partial derivatives), and on the regulatory framework (via the sanctions schedule $z(\delta)$ ). In order to go one step further in the analysis, without embarking in cumbersome calculations, we specify more precisely these functions.

Simplifying Assumptions : Now, for the sake of simplicity, we assume :

$$
\text { (a) } z(\delta)=\gamma \frac{\delta^{2}}{2}
$$

and

(b) $p(x, y)=p(k)$,

where $k=\frac{x}{y}$, and $p(k)>0$ if $k>0$, and $p^{\prime}(k)>0$ if $k<<\infty$. Assumption (b) is a classic one in the rent-seeking or conflict literature (see e.g. Neary, 1997, Grossman and Kim, 1995). Assumption (a) is clearly made for convenience, and the parameter $\gamma$ determines the (marginal) severity of the punishment schedule.

Using these two simplifying assumptions, as well as the efficient risk-taking condition (2), mutatis mutandis, we can transform the equilibrium conditions (7) and (8) into :

$$
\begin{aligned}
& \frac{p^{\prime}(k)}{y}=\frac{1}{\gamma \delta^{2}}, \\
& \frac{p^{\prime}(k) x}{y^{2}}=\frac{2}{\eta \gamma \delta^{2}} .
\end{aligned}
$$

Then, the sub-game perfect equilibrium can be calculated analytically, using the following definitions. 


\section{Definitions : Define}

(i) $k^{*}=2 / \eta$, as the equilibrium ratio of lobbying efforts by the two farmers,

(ii) $p^{*}=p\left(k^{*}\right)$, as the equilibrium probability of inspection, and

(iii) $\xi=p^{\prime}\left(k^{*}\right)$, as the equilibrium sensitivity of the regulatory framework to political interference.

Notice, from (i), that the poor farmer will put in the lobbying contest more than twice the effort put by the rich farmer. Although this result is to some extent model-specific, it illustrates the disadvantage resulting from being located downstream. Now, using these definitions, one can prove the following proposition.

Proposition 4 : The sub-game perfect equilibrium of this game is such that :

(i) $\delta^{*}=\frac{1}{\gamma p^{*}}$,

(ii) $\beta^{*}=\frac{1-\eta / 2}{\gamma p^{*}}$,

(iii) $x^{*}=\frac{2 \xi}{\eta \gamma p^{*^{2}}}$,

(iv) $y^{*}=\frac{\xi}{\gamma p^{* 2}}$.

This set of simple analytical results allows to derive easily some useful comparativestatic predictions. In the following, we use $\xi$ as a parameter describing the extent of political interference in the functioning of the irrigation system ${ }^{10}$; we further define $\pi$ as a parameter describing the level of the probability of inspection, in order to clearly distinguish in the comparative static exercise the impact of an autonomous increase in the enforcement probability from the impact of an increased sensitivity of the system to political interference. In other words, we are defining the function $p(x, y)$ as $p(k, \xi, \pi)$, such that $\frac{\partial p^{*}}{\partial \xi}=0$, and $\frac{\partial p^{*}}{\partial \pi}=1$. Under this convention, the sub-game perfect equilibrium is determined by four parameters, $\eta, \pi, \gamma$, and $\xi$, which capture the relevant aspects of the institutional environment

\footnotetext{
${ }^{10} \xi$ is akin to the decisiveness parameter in Hirshleifer (1995).
} 
in which the game takes place. We can thus summarise the comparative statics of this equilibrium as in table 2 .

Table 2 : Comparative Statics of the Sub-Game Perfect Equilibrium

\begin{tabular}{|c|c|c|c|c|}
\hline & $\eta$ & $\pi$ & $\gamma$ & $\xi$ \\
\hline$p^{*}$ & - & + & 0 & 0 \\
\hline$\delta^{*}$ & + & - & - & 0 \\
\hline$\beta^{*}$ & $?+$ & - & - & 0 \\
\hline$x^{*}$ & $?+$ & - & - & + \\
\hline$y^{*}$ & + & - & - & + \\
\hline
\end{tabular}

Proof : see appendix.

Note : The impacts of $\eta$ on $\beta^{*}$ and $x^{*}$ are ambiguous, as a rich farmer with more bargaining power gets more additional water, at a cheaper implicit price, and pays for a larger share of the expected cost of sanctions, making it worthwhile to invest more resources in lobbying, with a view to reduce this cost. The impact on the lobbying effort by the poor farmer will thus depend on the cross-second derivative of the $p(-)$ function. However, these two impacts are positive if $\xi>\frac{p^{*} \eta^{2}}{2(2-\eta)}$ and $\xi>\frac{\eta p^{*}}{4}$, respectively, i.e. even for fairly small values of $\xi$.

Examining table 2 shows the relative importance of the different parameters describing the institutional framework in determining the results. The quantity of water diverted and the amount of the baksheesh are affected by the bargaining power of the rich farmer, by the autonomous level of the probability of inspection, and by the severity of the sanctions schedule, but not by the sensitivity of the regulatory framework to the farmers' lobbying efforts. Hence, in this model, the latter can be regarded as a pure waste of resources, as the rent-reducing and the rent-defending efforts offset each other. Consequently, insulating the irrigation bureaucracy from political interference would be a Pareto-improving move. However, it is not clear how this could be achieved in the case of the Chishtian area, where the tradition of political interference with the bureaucracy is well entrenched, as it is in many other parts of the world. 
Before turning to the empirical analysis, we can go one step further in the comparison of our results with the literature, as announced in the introduction. In the literature on corruption, one can distinguish a line of analysis based on market power, and another line of inquiry based on asymmetric information. Our analysis clearly belongs to the latter, and is somehow related to Laffont and N'Guessan (1999). They analyze the case of a regulated firm, where the regulator hires a supervisor to discover some useful information about the firm, in order to reduce its remaining rent. With a given probability, the supervisor gets the desired verifiable information, and will sell it to the regulator at a price that the regulated firm cannot top up to defend its rent. In our model, there is no regulator, and the poor farmer is the one that seeks to reduce the informational rent shared by the rich farmer and the irrigation manager. The ability of the latter two agents to exploit this rent is reduced by the threat of sanction, the probability of which is affected by the resources invested competitively in political lobbying by the two farmers. The socio-political and regulatory frameworks thus play in our model a part which is similar to the one played by the supervisor in the LaffontN'Guessan model, but with an endogenous probability of discovering the relevant information, as a function of the lobbying efforts by the two sides. Moreover, whereas the Laffont-N'Guessan model is based on the principal-agent framework, no actor is able to extract all the rent in our model, where the bargaining power of the rich farmer plays an important part in shaping the Nash equilibrium, as well as in the empirical analysis that follows. The three actors of the Laffont-N'Guessan model (regulator, supervisor, regulated firm) are hierarchically ranked, whereas the four actors of our model (including the institutional framework) are treated more symmetrically: the rich farmer and the irrigation official bargain over the corrupt transaction, while the two farmers play simultaneously in the political contest.

\section{Empirical Analysis}

The empirical analysis performed here exploits the unique characteristic offered by the irrigation system for testing a model of corruption behavior, namely that the corrupt transaction leaves a measurable physical mark on the infrastructure, as it results in the 
enlargement of the outlets relative to their official size. The actual dimensions of the 503 outlets along the 14 distributaries of the Chishtian sub-division have been measured at the beginning of the period when the canals were closed in January $1996^{11}$. These dimensions have been compared to their official characteristics collected from the books of the subdivisionary engineer of Chishtian. Because there is always some random error in the building of the outlets, we have considered that an outlet has been voluntarily enlarged if at least one of its dimensions exceeds the official figure by more than two centimeters. This threshold has been selected after discussions with several farmers and low-ranking officials, and seems to reflect well the normal margin of error. Hence, our dependent variable is a dummy variable taking the value one if an outlet has been voluntarily enlarged, according to this criterion ${ }^{12}$.

Now, we need to adapt the insights gathered from the simple theoretical model analyzed in the previous section to the complexity of the real world. We have focused on the demand for tampering with the outlet by the upstream farmer, while the downstream farmer was defined by the fact that the supply of water that he faced was below his entitlement. In the real world, things are more complicated, because most farmers are located both upstream and downstream, relative to some other farmers. Along a gravitational canal, almost every farmer is physically in a position to divert more water from the distributary than he is officially entitled to, for at least part of the agricultural season, while occasional (and partial) shortages occur for the farmers located downstream, the more frequently, the further away they are from the canal head. Hence, almost all the farmers are in a sense 'upstream farmers', but the value of the extra discharge that they can obtain by tampering with the outlet is affected by such supply variables as the distance from the canal head, the variability of the

\footnotetext{
${ }^{11}$ Hence, the sample used here is much larger than the one used in Rinaudo, Strosser and Thoyer (2000), and has been collected two years later. Moreover, they do not use their data for any econometric estimation.

${ }^{12}$ The ideal dependent variable would have been the increase in the discharge due to the alteration of the outlet, assuming that the two parties to the bargain perceived it correctly on average. However, we had to give up this idea, because it was intractable to compute it from our measures for all the outlets, for several reasons. First, the increase in the discharge is a non linear function of the increase in the different dimensions (height and width), and depends on its height relative to the water level in the canal, which was not measured. Second, the alterations to the outlets are not generally geometrically regular, as the bargaining over the bribe often takes place while the builders are 'repairing' the outlet, to increase the bargaining power of the PIPD official, so that only a few bricks, or even part of them, are removed, and its final shape is often non standard. In our sample this is the case in 62 out of 95 cases of significantly enlarged outlets. No known hydraulic formula can then be applied. Therefore, we have to be content with our dichotomous variable.
} 
flow in the distributary, etc. Hence, while the expected sanction facing the irrigation system official is related to the size of the enlargement of the outlet, which is the verifiable information that can be used in a court, the expected benefit for the farmer is related to the expected value of the increased discharge from the outlet, which depends on the supply-side variables described above. Then it is clear that the corrupt transaction will not occur if the latter are such that the expected value of the additional water becomes too low relative to the expected cost of the sanction. The bargaining set will then be empty. Hence, we need to bring supply-side variables into the empirical analysis.

Formally, this argument can be written as follows. In order to take into account these supply effects, we decompose $\delta=v \theta$, where $\theta$ is the size of the enlargement of the outlet, and $v$ is the expected value of the additional flow of water appropriated, which depends on supply-side variables, as suggested above. Assume that the possible sanctions depend on the former $(z=z(\theta))$, while $v$ is exogenous. Then, the efficient risk-taking condition becomes :

$$
\begin{aligned}
& \theta>0 \text { if } z^{\prime}(\theta)=v / p^{*}, \\
& \theta=0 \text { if } z^{\prime}(0) \geq v / p^{*},
\end{aligned}
$$

In the theoretical analysis of the previous section, we have described the special case where $v=1$ for the upstream farmer, and $v=0$ for the downstream farmer. For the empirical analysis, we need to extend this framework by treating $v$ as a continuous variable, in order to accommodate intermediate positions, and even allow for possible negative values, to allow for the effects of waterlogging. The latter refers to the cases where the underground water emerges on the surface, with detrimental effects on the crops. Hence, the decision to tamper with the outlet or not, as described in (13) and (14), can be analyzed using the dichotomous dependent variable described above.

Among the other useful pieces of information available in the books of the subdivisionary engineer, we have collected the water rights, which describe the quantity of water supposed to be delivered by the outlet, which allows to measure the relative scarcity of the water in the watercourse (before tampering with the outlets), when divided by the number of 
hectares supplied by each outlet. The latter was also collected from these books. A small water right per hectare should indicate the high value of the additional water obtained by corrupting the official. We have also collected the distance of the outlet from the canal head, as the theoretical model predicts that the farmers located upstream are more likely to divert water. We have used the daily measurements performed by the IIMI of the flow of water in each distributary during the winter 1993-1994 and the summer 1994 for computing the average flow, which we express as a percentage of the official figure, as well as the coefficient of variation of the flow, in order to measure its variability. These two variables should also affect the value of the additional water to the farmers, with a negative impact for the former, and a positive one for the latter. Another piece of technical information affects the value of the additional water, namely the emergence on the surface of the ground water, or waterlogging. Because of the deficiency of the drainage system, the ground water comes close to the surface on some plots, with detrimental effects on the crops. Then, obviously, the value of additional water becomes negative. So, for each outlet, we have computed the percentage of the plots affected by this problem in the corresponding watercourse area. Similarly, one would expect that the presence and use of tube wells in a watercourse area should reduce the need to acquire additional water from the canal. However, in some areas, the salinity of the ground water is such that the water from the well can only be used for irrigation if it is mixed with a large enough quantity of canal water, in order to dilute the excessive salinity. Hence, we have included in the analysis a variable measuring the density of wells in the watercourse area, as well as the fraction of the farmers who only use well water for irrigating their plots in summer, which is an indirect measure of the quality of the ground water.

The game-theoretic model analyzed in the previous section emphasizes the importance of the bargaining power of the farmers in their dealings with the PIPD officials in determining the quantity of water diverted by the upstream farmers. In this model, we have treated as a unitary farmer what is in fact a group of farmers supplied by a given outlet. The data discussed in section 2 have shown that in general, the collective action problems are not serious at this level. Nevertheless, we may expect that the bargaining power of the group will 
be affected by the presence of strong leaders, and by the homogeneity of the group. In order to capture the strength of the leadership, we use several variables. First, we use a dummy that indicates if there are plots in the watercourse area that belong to at least one of the powerful landlord families described in section 1 . We also use the percentage of the farmers in the watercourse area that own more than 10 hectares, which they do not necessarily cultivate themselves, and the percentage of farmers that cultivate more than eight hectares, which they do not necessarily own, and may use on a fixed rent basis. The latter should measure pretty well the importance of the 'capitalist' farmers concerned by the outlet, as eight hectares is regarded as the minimum holding size for a tractor to become profitable. In the same vein, we also use the percentage of sharecroppers in the group of farmers concerned by the outlet. However, the impact of this variable is hard to predict, as it can go either way : on the one hand, it is well known, from Marshall and others, that the sharecropping contract might reduce the marginal incentive to increase production, and thus to acquire some extra water, but on the other hand, it provides an incentive to the land owner to get involved in the bargaining, in order to compensate for the weak position of the sharecropper, who usually belongs to the poorest farmers.

In addition, there exist in the Chishtian area various farmers associations, which have been created in the 1980 s to supervise the lining with concrete of the tertiary canals, as part of a nation-wide subsidized rehabilitation campaign. We use a dummy variable to indicate whether such an association has been created in the past within the group of farmers concerned by each outlet. However, this variable could play an ambivalent role, as it suggests that the group has some ability to solve its collective action problems ${ }^{13}$, and thus has some enhanced bargaining power, on the one hand, while it could also signal that the group is fit for lobbying politicians, on the other hand, as associations probably control a sizable number of votes, with a small cost of organization, while we know from our model that the lobbying

\footnotetext{
${ }^{13}$ See Bardhan (1984, pp. 218-219) on the role of local water committees in India, with a discussion of the conditions that facilitate their creation. Bardhan (2000) analyzes empirically community level cooperation in water management, using a sample of 48 irrigation communities in South India. He emphasizes the negative role of inequality of land holding, and of government involvement, and the positive influence of social homogeneity and small group size.
} 
efficacy should not affect significantly the outcome. So, the overall impact will probably depend on the importance of the collective action effect relative to the political weight effect.

Similarly, we use a dummy variable for capturing the political influence of some farmers concerned by an outlet, which indicates whether there is at least one plot in the watercourse area that belongs to a member of parliament, provincial or federal, or to a toplevel civil servant. This is an important test variable for our theoretical framework, as the first and superficial intuition about such a variable would be that it affects significantly the probability of a corrupt transaction taking place, while our theoretical construct suggests that it should have no significant impact, as its potential effect is offset by the lobbying efforts of the downstream farmers, in the sub-game perfect equilibrium. Lastly, we use dummy variables to account for the ethnic origin of the farmers. We have first three dummies that indicate the presence in the group concerned by the outlet of farmers of local origin, of settlers from central Punjab, or of refugees from India. In addition, we use another dummy that accounts for the homogeneity of the group of farmers, and takes the value one if the group is of purely local origin, without any settler or refugee in the group. Interviews in the field suggest that these groups, which have been present for the longest period of time, are the most prone to corrupt practices. Their bargaining power may come both from their homogeneity and from their stronger 'legitimacy'.

Table 3 presents some descriptive statistics. Columns one and two describe the average values of the different variables, splitting the sample between the sets of unchanged outlets and enlarged ones, while the third column gives the full sample averages. A glance at these data suggests that the ethnic origin, and homogeneity, of the groups of farmers matter for the probability of engaging in corrupt practices, as does the presence of 'capitalist' farmers and of plots of land belonging to the powerful landlord families. It also suggests that the quality of the groundwater, and its proximity to the surface, do matter as well. However, these observations are only suggestive, and a proper econometric analysis is required to estimate the partial impacts of each of these variables.

The results of the estimation of a probit regression explaining whether the outlets have been tampered with or not are presented in table 4. Equation 1 includes all the variables 
presented above, and shows that many of them turn out not to be significant. Equation 2 is a more parsimonious one, derived from equation 1 by (i) deleting the insignificant variables, and (ii) replacing the three dummies indicating the ethnic origins of the farmers, by one dummy indicating that the group of farmers concerned by the outlet is only comprised of farmers of local origin. Most of the variables have the predicted signs, while the ambiguous ones turned out non significant. Notice that the presence of owners of more than 10 hectares in the watercourse area affects the outcome with a negative sign. This suggests that these land owners, who usually rent out their land for a fixed rent, do not internalize the pecuniary externality that could result from their greater involvement in the bargaining over the enlargement of the outlet, which could entail an increase in the rental rate in the long run. The larger their number, the more they seem to free ride on one another. We thus have here an example where 'increased competition', in the land rental market, reduces corruption, as in Bliss and Di Tella (1997). It is interesting to notice that the presence of farmers of local origin is not enough to give the group a strong bargaining power. Its homogeneity, as captured by the absence of immigrants in the group, is what really matters.

An important test for our theoretical framework is the absence of effect of the variables that reflect political influence. Our model suggests that the sensitivity of the regulatory framework to the lobbying efforts of the farmers should not affect the quantity of water diverted. Our 'political influence' variable should be strongly related to this parameter, and turns out not to be significant. The same applies to the 'farmers association' variable. Thus, on the face of it, these negative results seem to vindicate our theory. However, one might argue that our two political variables may in fact be poor proxies, that capture only in an imperfect way the sensitivity of the system to political interference. This potential criticism has to be accepted, but we have been unable to get a better proxy in our field work. Nevertheless, the general outlook of the econometric results provide some support to our theoretical framework, confirming apparently that the issues of illegal appropriation and corruption can fruitfully be analyzed in a theoretical framework that pays due attention to the formal and informal institutional environment in which the game takes place. 
Table 3 : Characteristics of the Watercourses and their Agricultural Population According to the State of their Outlets.

\begin{tabular}{|c|c|c|c|c|}
\hline Variables & $\begin{array}{c}\text { Unchanged } \\
\text { Outlets } \\
\end{array}$ & $\begin{array}{l}\text { Enlarged } \\
\text { Outlets } \\
\end{array}$ & All & $\begin{array}{l}\text { Significance } \\
\text { of Difference } \\
\end{array}$ \\
\hline Number & $328(77 \%)$ & $95(23 \%)$ & $423(100 \%)$ & - \\
\hline \multicolumn{5}{|l|}{ Pop. Origin (\% of outlets) } \\
\hline Settlers (1932-1947) & $9 \%$ & $4 \%$ & $8 \%$ & $* * *$ \\
\hline Refugees $(>1947)$ & $52.5 \%$ & $41 \%$ & $50 \%$ & $* * *$ \\
\hline Local & $88 \%$ & $90 \%$ & $89 \%$ & ns \\
\hline Pure Local & $43 \%$ & $58 \%$ & $49 \%$ & $* * *$ \\
\hline \multicolumn{5}{|l|}{ Farm Types (\% of outlets) } \\
\hline$>8$ Hectares Cultivated & $9.5 \%$ & $12.5 \%$ & $10 \%$ & $* * *$ \\
\hline$>10$ Hectares Owned & $9.8 \%$ & $9.6 \%$ & $9.8 \%$ & $\mathrm{~ns}$ \\
\hline Sharecroppers & $12 \%$ & $12 \%$ & $12 \%$ & ns \\
\hline $\mathrm{Nb}$ of Tractors per Farm & 0.2 & 0.22 & 0.2 & $\mathrm{~ns}$ \\
\hline $\mathrm{Nb}$ of Wells per Farm & 0.22 & 0.22 & 0.22 & ns \\
\hline \multicolumn{5}{|l|}{ Influence (\% of outlets) } \\
\hline Powerful Families & $47 \%$ & $68 \%$ & $52 \%$ & $* * *$ \\
\hline Politician or Top Official & $25 \%$ & $22 \%$ & 25 & ns \\
\hline \multicolumn{5}{|l|}{ Water Resources } \\
\hline Water Rights & $627 \mathrm{~mm} / \mathrm{ha}$ & $613 \mathrm{~mm} / \mathrm{ha}$ & $624 \mathrm{~mm} / \mathrm{ha}$ & \\
\hline$\%$ Farmers Using Only Well & $12.5 \%$ & $7.5 \%$ & $11.5 \%$ & ns \\
\hline $\begin{array}{l}\% \quad \text { Watercourses with } \\
\text { Surfacing Groundwater }\end{array}$ & $9 \%$ & $1.5 \%$ & $8 \%$ & $* * *$ \\
\hline \multicolumn{5}{|l|}{ Other } \\
\hline Yearly Cultural Intensity & $173 \%$ & $178 \%$ & $174 \%$ & ns \\
\hline
\end{tabular}


Table 4 : Probit Equation Explaining Outlet Enlargement

\begin{tabular}{|c|c|c|}
\hline Explanatory Variables & Equation 1 & Equation 2 \\
\hline Number of Observations & 423 & 423 \\
\hline \multicolumn{3}{|l|}{ Water Supply } \\
\hline Water Right & $-0.002(-1.82)^{*}$ & $-0.0016(-2.1)^{* *}$ \\
\hline Distance to Canal Head & $-0.003(-1.13)$ & $-0.0045(-1.7)^{*}$ \\
\hline Average Flow/Official Flow & $-0.39(-0.55)$ & $-0.84(-1.8)^{*}$ \\
\hline Flow Variability & $1.05(0.8)$ & $-\ldots$ \\
\hline \multicolumn{3}{|l|}{ Groundwater Access } \\
\hline Wells Density & $-0.007(-0.18)$ & --- \\
\hline Groundwater Quality & $-0.003(-0.94)$ & --- \\
\hline Surface Groundwater & $-0.06(-1.54)$ & $-0.06(-1.7)^{*}$ \\
\hline \multicolumn{3}{|l|}{ Farmers Characteristics } \\
\hline$>8$ Hectares Cultivated & $0.02(2.6)^{* * *}$ & $0.022(2.5)^{* * *}$ \\
\hline$>10$ Hectares Owned & $-0.02(2.14)^{* *}$ & $-0.02(2.25)^{* *}$ \\
\hline Sharecroppers & $-0.003(0.68)$ & --- \\
\hline Landlord Families & $0.46(2.65)^{* * *}$ & $0.43(2.65)^{* * *}$ \\
\hline Political Influence & $-0.05(-0.27)$ & --- \\
\hline Farmers Association & $-0.18(-0.91)$ & --- \\
\hline \multicolumn{3}{|l|}{ Ethnic Origin } \\
\hline Local & $-0.02(0.08)$ & --- \\
\hline Settlers & $-0.67(1.8)^{*}$ & --- \\
\hline Refugees & $-0.24(-1.47)$ & --- \\
\hline Purely Local & --- & $0.33(2.1)^{* *}$ \\
\hline Intercept & $-0.17(-0.12)$ & $0.42(0.75)$ \\
\hline Log Likelihood & -201.25 & -205.33 \\
\hline $\begin{array}{l}\text { Log Likelihood (Restricted } \\
\text { Model }\end{array}$ & -225.3 & -225.3 \\
\hline Cragg and Uhler ${ }^{14}$ Pseudo $\mathrm{R}^{2}$ & 0.14 & 0.17 \\
\hline Well Predicted Observations & $78.5 \%$ & $78.5 \%$ \\
\hline
\end{tabular}

Note : $t$-statistics in parentheses. Significance levels : * $10 \%, * * 5 \%, * * 1 \%$.

\footnotetext{
${ }^{14}$ See Maddala (1992, pp.332-335) for a discussion of different versions of the pseudo $\mathrm{R}^{2}$.
} 


\section{Conclusions}

In this paper, we have analyzed a game-theoretic model of illegal appropriation of irrigation water, involving corruption and political interference, that helps to articulate in a coherent framework the main elements gathered in our field work in the Chishtian subdivision of the Indus Basin Irrigation System. We have decomposed the action in two stages, involving first a lobbying contest between the two farmers, where the poor farmer tries to increase the expected cost to the irrigation official of indulging in a corrupt transaction with the rich farmer, while the rich farmer's lobbying efforts are aimed at offsetting this pressure. In the second stage, the rich farmer and the irrigation official bargain over a secret deal, which involves the granting of additional water in return for a bribe.

Our data from the field provide a unique opportunity to test such a micro-economic model of corrupt behavior, because the deal between the rich farmer and the irrigation official leaves a measurable mark on the irrigation infrastructure, as the delivery of additional water requires the enlargement of the outlet. This data has been collected, and used for estimating a probit equation, relating the outlet enlargement to various variables reflecting both technical constraints, like the groundwater coming to the surface, or the distance of the outlet to the canal head, and the socio-economic characteristics of the farmers involved. The results seem to vindicate the view that corruption is positively affected by the bargaining power of the prominent farmers in the groups concerned, as well as by the ethnic homogeneity of the group of farmers of local origin.

Our results are probably not firm and detailed enough to lead to sweeping policy conclusions. Nevertheless, two points seem to emerge from this analysis. First, the root cause of the complicated socio-political construct of corruption-cum-political interference that has developed around the irrigation system seems to be the asymmetric information that allows the rich farmers and the irrigation officials to strike secret deals at the expenses of the poorer farmers located downstream. This asymmetric information is the main obstacle to the emergence of an efficient water market. Hence, any proposed reform should aim at improving the transparency of the functioning of the irrigation system, in order to allow the poor farmers 
to observe the modifications of the outlets that are performed upstream. As we have been able to collect the information relative to the enlarged outlets in the Chishtian area, one might imagine that it is possible to organize the poorer farmers in such a way that they could collect this information at low cost. However, because of the distances involved, and the time required for collecting this information, this does not seem realistic. A simpler solution might be implemented, that would reduce the cost to the farmers. Gauges could be installed at regular intervals along the distributary. On each gauge, a graduation would show the normal level of water so that farmers inspecting the canal from its tail to its head could observe where, along this canal, the water level drops below its normal level. Such a simple measurement device, if properly maintained, should help the tail farmers to identify the outlets drawing more water than their due share. The cost of inspection would be significantly reduced as farmers would not have to measure the dimensions of the outlets orifice, which lies under the water line during most of the year. Also, water associations established at the distributary level, as are currently tested in a few pilot projects (Bandaragoda, 1999), could be made responsible for financing the costs related to the monitoring of the gauges.

Then, a problem of pre-commitment arises, standing in the way of the establishment of an efficient water market. Assume for the sake of the argument, that the poor downstream farmers can thus observe the diversion of water at low cost, all along the agricultural season. They could thus offer ex ante a contract to the rich farmers located upstream, for refraining from diverting water beyond their quota, or to exceed it just by an agreed upon quantity, if they had the capacity to pre-commit to the payment of the price ex post, when the season is over $^{15}$. One may imagine that this commitment capacity could be brought about by the creation of an institution that would collect the money from the downstream farmers ex ante, and would pay the upstream farmers ex post, if they had actually refrained from tampering with the outlets beyond the agreement. Such an institution could in fact bear most of the cost of monitoring the water levels and the outlets, at the end of the season, and could also compensate all the cross-payments among farmers, in order to pay only the balances. However, such an intellectual construct, appealing as it seems at first glance, would probably

\footnotetext{
${ }^{15}$ Tenure insecurity from one year to the next is probably the most important cause of this commitment problem.
} 
trigger a much wilder corruption scramble, and raise momentous credibility problems, at least in the case under study. Moreover, as it involves basically the payment by the poor downstream farmers of bribes to the richer upstream farmers for not encroaching on their entitlements, such a system would no doubt antagonize the basic sense of equity shared by most people, and would thus be politically more difficult to implement.

Second, it seems that the political contest in which the farmers engage to reduce or defend the informational rent derived from the basic information asymmetry brought out above is a pure waste of resources, that could be avoided by insulating the functioning of the system of control over the irrigation officials, and the probability of sanction, from political interference. This is more easily written than implemented, as the tradition of political interference with the working of the bureaucracy seems to be strongly entrenched in Pakistan, and to have been so for a long time, as it is in many other parts of the world. Maybe the current system of corruption-cum-political interference, which allows people to point the finger of suspicion at the rich, and to engage in political action against them, allows them to experience a sense of enhanced political responsibility and dignity that pays for the resources wasted in competitive lobbying.

\section{Appendix : Proofs for Table 2}

From the expressions presented in proposition 4, we can derive the following derivatives :

$$
\begin{aligned}
& \frac{d k^{*}}{d \eta}=-\frac{2}{\eta^{2}}<0 ; \quad \frac{\partial p^{*}}{\partial \eta}=-\frac{2 \xi}{\eta^{2}}<0 ; \quad \frac{\partial \delta^{*}}{\partial \eta}=\frac{2 \xi}{\gamma p^{*^{2} \eta^{2}}>0} \\
& \frac{\partial \delta^{*}}{\partial \gamma}=\frac{-1}{\gamma^{2} p^{*^{2}}}<0 ; \quad \frac{\partial x^{*}}{\partial \eta}=\frac{2 \xi}{\gamma \eta^{2} p^{* 3}}\left(\frac{4 \xi}{\eta}-p^{*}\right) \\
& \frac{\partial \beta^{*}}{\partial \eta}=\frac{(2-\eta) 2 \xi-p^{*} \eta^{2}}{2 \eta^{2} \gamma p^{* 2}} ; \quad \frac{\partial \beta^{*}}{\partial \gamma}=\frac{-(1-\eta / 2)}{\gamma^{2} p^{*}}<0
\end{aligned}
$$




$$
\frac{\partial y^{*}}{\partial \eta}=\frac{4 \xi^{2}}{\gamma \eta^{2} p^{* 3}}>0 ; \quad \frac{\partial y^{*}}{\partial \xi}=\frac{1}{\gamma p^{*^{2}}}>0 ; \quad \frac{\partial y^{*}}{\partial \gamma}=\frac{-\xi}{\gamma^{2} p^{*^{2}}}<0 .
$$

The other results in table 2 are straightforward.

\section{References}

Bandaragoda, D. J. 1999. “Institutional Changes and Shared Management of Water Resources in Large Canal Systems : Results of an Action Research Program in Pakistan.” Research Report N³5, International Water Management Institute : Colombo.

Bandaragoda, D. J. and S. Rehman. 1996. "Warabandi in Pakistan Canal System : Widening Gap Between Theory and Practice.” Country Paper, Pakistan Nº.7, IIMI : Colombo.

Bardhan, Pranab K. 1984. Land, Labor, and Rural Poverty. Essays in Development Economics. Columbia University Press : New York.

Bardhan, Pranab K. 2000. "Irrigation and Cooperation: An Empirical Analysis of 48 Irrigation Communities in South India." Economic Development and Cultural Change, : 845-65.

Besley, Timothy. 1995. "Property Rights and Investment Incentives : Theory and Evidence from Ghana." Journal of Political Economy 103 (5) (October) : 903-37.

Bhutta, and Vander Velde. 1992. "Equity of Water Distribution along Secondary Canals in Punjab, Pakistan." Irrigation and Drainage Systems 6 : 161-77.

Bliss, Christopher, and Rafael Di Tella1997. “Does Competition Kill Corruption ?” Journal of Political Economy 105 (5) (October) : 1001-23.

Davies, Jennifer. 2004. "Corruption in Public Service Delivery: Experience from South India's Water and Sanitation Sector." World Development 32 (1): 53-71.

de Meza, David, and J.R. Gould. 1992. "The Social Efficiency of Private Decisions to Enforce Property Rights.” Journal of Political Economy 100 (3) (June) : 561-80.

Government of Pakistan. 1993. "Report of the Prime Minister Task Force on Agriculture." Ministry of Agriculture : Islamabad. 
Grossman, Herschel I. and Minseong Kim. 1995. "Swords or Plowshares ? A Theory of the Security of Claims to Property." Journal of Political Economy 103 (6) (December):1275-88.

Jacoby, Hanan, Rinku Murgai, and Saeed Ur Rehman. 2003. "Monopoly Power and Distribution in Fragmented Markets: The Case of Groundwater." Review of Economic Studies (forthcoming).

Hirshleifer, Jack. 1995. “Anarchy and Its Breakdown.” Journal of Political Economy 103 (1) (February) : 26-52.

Kuper, M. (1997). “Irrigation Management Strategies for Improved Salinity and Sodicity Control.” Ph.D. Dissertation : Wageningen Agriculture University.

Laffont, Jean-Jacques, and Tchétché N'Guessan. 1999. “Competition and Corruption in an Agency Relationship.” Journal of Development Economics 60 : 271-295.

Laffont, Jean-Jacques, and Jean Tirole. 1993. A Theory of Incentives in Procurement and Regulation. New York: MIT Press.

La Porta, Rafael, Florencio Lopez-de-Silvanes, Andrei Shleifer, and Robert. W. Vishny. 1998. “Law and Finance.” Journal of Political Economy 106 (6) (December) : 1113-55.

Maddala, G. S. 1992. Introduction to Econometrics. London: Prentice Hall.

Murgai, Rinku, Paul Winters, Elisabeth Sadoulet, and Alain de Janvry 1999. "Localized and Incomplete Mutual Insurance." Unpublished manuscript, University of California : Berkeley.

Neary, Hugh M. 1997. “A Comparison of Rent-Seeking Models and Economic Models of Conflict." Public Choice 93 : 373-88.

North, Douglass C. 1990. Institutions, Institutional Change and Economic Performance. Cambridge, Mass.: Cambridge University Press.

Ray, Isha, and Jeffrey Williams. 1999. "Evaluation of Price Policy in the Presence of Water Theft." American Journal of Agricultural Economics 81 (November): 928-41.

Ray, Isha, and Jeffrey Williams. 2002. "Locational Asymmetry and the Potential for Cooperation on a Canal." Journal of Development Economics 67:129-155. 
Rinaudo, Jean-Daniel (2000). "Rentes, corruption et lobbying politique. Obstacles aux réformes dans le secteur irrigué au Pakistan.” Ph. D. Thesis, CERDI : ClermontFerrand.

Rinaudo, Jean-Daniel, Pierre Strosser, and Thierry Rieu. 1997. "Linking Water Market Functioning, Access to Water Resources and Farm Production Strategies : Examples from Pakistan." Irrigation and Drainage Systems 11: 261-80.

Rinaudo, Jean-Daniel, Pierre Strosser, and Sophie Thoyer. 2000. "Distributing Water or Rents? Examples from a Public Irrigation System in Pakistan.” Canadian Journal of Development Studies 21 (1): 105-130.

Rubinstein, Ariel 1982. "Perfect Equilibrium in a Bargaining Model.” Econometrica 50 : 20711.

Sen, Amartya. 1981. Poverty and Famines. An Essay on Entitlement and Deprivation. Oxford: Clarendon Press.

Shleifer, Andrei, and Robert W. Vishny 1993. "Corruption.” Quarterly Journal of Economics 108 (3) (August): 599-617.

Strosser, Pierre. 1997. “Analyzing Alternative Policy Instruments for the Irrigation Sector : An Assessment of the Potential for Water Markets Development in the Chishtian SubDivision.” Ph.D. Dissertation : Wageningen Agriculture University.

Tullock, Gordon. 1967. "The Welfare Costs of Tariffs, Monopolies, and Theft." Western Economic Journal 5 (June): 224-32.

Ullah, H. 1994. "Participatory Irrigation Management : a Case Study of Azim Distributary." Technical Paper, Punjab Irrigation and Power Department : Bahawalpur (Pakistan).

World Bank. 1994. "Pakistan Irrigation and Drainage : Issues and Options." Report $\mathrm{N}^{\circ}$ 11884-PAK, World Bank : Washington, D.C. 